INTERNATIONAL HIGHER EDUCATION, Number 72. Summer 2013

Pages 13-15

\title{
The Implications of Excellence in Research and Teaching
}

JOHANNES WESPEL, DOMINIC ORR, and MICHAEL JAEGER

Johannes Wespel is a researcher at the HIS-Institute for Research on Higher Education in Hannover, Germany. E-mail: wespel@his.de. Dominic Orr is a project leader at the same center. E-mail: orr@his.de. Michael Jaeger is deputy head of the same center. E-mail: m.jaeger@his.de.

In recent years, national initiatives to foster scientific excellence have become popular as a steering and funding instrument for public higher education systems in many Organization for Economic Cooperation and Development (OECD) countries, most prominently in Germany with its Excellence Initiative. This contribution considers if and how university teaching is taken into consideration in various existing excellence initiatives. The two main results are that (a) teaching and learning play a subordinated role in excellence-funding schemes for universities, and (b) there is less uniformity with regard to the definition of and the programs to promote excellence in teaching than for research.

\section{EXCELLENCE INITIATIVES}

Official descriptions of state-run funding schemes targeting scientific excellence were analyzed for an OECD working group, and the results were discussed at an OECD seminar for national experts. The data material spans 24 such schemes 
from 16 countries on four continents. The analysis shows that a prototypical design has emerged for excellence initiatives. A restricted number of centers composed of high-class scientists are singled out in a competitive, multistage process involving international peer reviewers and, in many cases, site visits. Selected centers receive generous state funding to carry out research schemes, albeit depending on positive progress and outcome evaluations. Funding periods are longer than for project funding. The average for the research sample is over six years, and further sustainability of the centers is an important objective of the funding schemes. Most initiatives have undergone several funding cycles since their inception. Political aims of excellence schemes are defined in a rather general fashion and are usually not per se linked to specific areas of science. The goals of raising the competitiveness of the national science system and sparking new synergies through cooperation between institutions and/or disciplines rank particularly high. Many excellence initiatives originate from a national innovation strategy, in which the public research sector represents a crucial building block.

\section{The Status OF Teaching}

Universities, the main target of the excellence initiatives surveyed in this project, serve as society's principal adapter between scientific research and its dissemination, by way of teaching and learning. It is, therefore, interesting to see in what way public funding supports this link. To this end, the program descriptions of the excellence initiatives are analyzed in the sample, in terms of whether and how teaching is integrated into the assessment criteria for 
proposals. It has been found that the vast majority of initiatives concentrate on research-related factors-such as, past merit in research, the innovativeness and feasibility of the proposed research project(s), and the utility of the outcomes. Teaching is not among the assessment criteria in most of the initiatives. Only a few cases include aspects of teaching specifically: Spain's International Campus of Excellence initiative (excellence in research and in teaching are weighted equally high); Ireland's Program for Research in Third-Level Institutions (impact on teaching and learning is one of four major assessment criteria); South Korea's World Class University Program (aims at creating new faculty environments, including teaching improvement); and Germany's Excellence Initiative (effects of research on teaching are one criterion among 15 different criteria).

The results show that the term "excellence," as used in state-run funding schemes, clearly gravitates toward research performance. Critics fear that the unique reputation given by an official excellence status, in connection with the considerable funds awarded to successful applicants, may encourage universitybased scientists to concentrate on research at the expense of teaching. It is mainly in the context of this debate that a few countries have launched separate, standalone initiatives to foster new and outstanding teaching concepts. Those teaching-excellence initiatives are clearly inspired by the research-centered excellence schemes, in terms of their structure and how the selection process is set up: international peers evaluate a pool of competing proposals in a qualitybased procedure, and funding is then restricted to the very best applicants. Examples of such initiatives are Finland's Centers of Excellence in University Education scheme, whose funded units are expected to play a key role in improving the quality and relevance of university education in a long-term 
perspective; the United Kingdom's Centers for Excellence in Teaching and Learning program, active between 2005 and 2010, supporting 74 centers of teaching and learning development at British universities; France's Initiatives d'excellence en formations innovantes ("excellence initiatives in innovative teaching"), launched in 2012 with the aim of funding innovative teaching projects with a role model function for other higher education institutions; and Germany's scheme, Exzellente Lehre ("excellent teaching"), providing funds for 10 selected higher education institutions implementing innovative teaching concepts.

\section{EXCELLENCE AND DIVERSITY}

A closer look at the specialized, teaching-excellence program descriptions reveals that the funded units as well as the concrete measures to achieve and sustain excellence are very diverse, even within the single initiatives. Eligible units can be departments, faculties, universities, time-bounded programs, or interinstitutional networks. They can be independent centers, attached to or identical with existing educational units. Supported measures include staff qualification, curricular reforms, skills development for students, establishing elearning offers, or strengthening the students' voice in university governance. This is in contrast to research-excellence initiatives, for which definitions of what excellence is actually about-and in what way it is best achieved-are rather more uniform across countries and initiatives. This finding is in line with a second juxtaposition: teaching excellence initiatives make the exemplary character of the proposed concepts-i.e., their transferability to other institutions 
and settings-a primary assessment criterion apart from the innovativeness of the concept as such. A comparable criterion is much less prominent in researchexcellence initiatives across the board. It thus appears that teaching-excellence initiatives generally play a different role from research excellence initiatives. Whereas in research, excellence schemes can be seen as a means to pinpoint scientific value creation through tried and tested operational patterns, and teaching initiatives have a more explorative character: they are expected to help clarify what excellent teaching is all about in the first place.

The hesitance to include teaching and learning in the major national excellence initiatives, described above, appears to be due to the lack of agreed procedures, standards, and measurements for excellence in teaching. It remains to be seen whether a more unified understanding of teaching excellence will emerge in time, or whether the diversity of approaches currently observable will remain-possibly as a result of the contextual and multifarious nature of the activity of teaching. If the emergence of teaching excellence cannot be found, it is likely that research will continue to determine the definition of overall excellence in higher education - $\mathrm{a}$ focus that obscures the huge challenges facing mass provision of higher education in a knowledge society. 